\title{
Transferability of decision-support tools
}

\author{
Roger B. Street ${ }^{1}$ (D) Patrick Pringle ${ }^{1}$ • \\ Tiago Capela Lourenço ${ }^{2} \cdot$ Mariana Nicolletti $^{3}$
}

Received: 2 September 2017 / Accepted: 24 July 2018 /Published online: 14 August 2018

(C) The Author(s) 2018

\begin{abstract}
The potential for transferring and translating existing adaptation to climate change decision-support tools for use in different settings provides both opportunities and challenges to those wanting to support such decisions in or for the targeted community/organisation. The opportunities are related to being able to build on an existing credible and tested tool and its supportive resources and foregoing the costs associated with developing such themselves. The challenges relate to taking advantages of the strengths of an existing tool whilst adapting it and its supportive resources such that they are fit for purpose and accepted within the targeted community/organisation. This paper identifies and explores these opportunities and challenges through those revealed as a result of transferring and translating the UKCIP Adaptation Wizard for use within other parts of the world and in different communities and organisations. Whilst drawing on a number of different examples of where the Wizard has been translated, this paper particularly focuses on the transfer and translation for use in Portugal and in Brazil. General lessons learnt related to transferring adaptation decisionsupport tools are identified and used to develop a practical framework. The intention is to provide insights that have broader implications for those considering transferring similar adaptation decisionsupport tools, but also for tool developers who want to see their tools being used more broadly.
\end{abstract}

\section{Introduction}

Over the past two decades, there has been a proliferation of decision-making methods and tools directed at supporting adaptation planning, including impacts, vulnerability, adaptation

This article is part of a Special Issue on 'Decision Support Tools for Climate Change Adaptation' edited by Jean Palutikof, Roger Street, and Edward Gardiner.

\section{Roger B. Street}

roger.street@ukcip.org.uk

1 Environmental Change Institute, Oxford University, Oxford, UK

2 Climate Change Impacts, Adaptation and Modelling (CCIAM), Centre for Ecology, Evolution and Environmental Change (cE3c), Faculty of Science, University of Lisbon, Lisboa, Portugal

3 Iniciativas Empresarias do FGV Centro De Estudos em Sustentabilidade, Sao Paulo, Brazil 
and risk assessment approaches (e.g. Willows and Connell 2003; PROVIA 2013, EEA Climate-ADAPT AST; VCCCAR CCA Navigator Tool 2012; BalticClimate 2012; see UNFCCC Adaptation Knowledge Portal for further examples) and monitoring and evaluation framings and approaches (see Bours et al. 2013 for examples). These methods and tools (hereinafter referred to as tools) ${ }^{1}$ have been designed for online and participatory application at trans-national, national and subnational levels. ${ }^{2}$

The proliferation of such tools is often directed at making the results of research available (supply-driven) rather than at addressing specific needs for decision support (demand-driven) (Capela Lourenço et al. 2016). The increase has also led to confusion and frustration being expressed by the very users the tools are intended to support (e.g. Climate UK 2012). Can I use an existing tool to support or inform my specific decision? Which tool (or tools) should I be using, why, where and when, and which should I not be using? Can I adapt an existing tool(s) I want to adopt for my specific use and, if so, what changes are needed and why? These questions and the associated challenges have led some within the adaptation community (users and developers) to question whether we need more tools or just ones that are more adaptable and/or transferable (questions raised during the relevant Adaptation Futures sessions in 2014 and 2016).

Interest in the potential for transferring and translating existing tools for use in different settings, along with the need to understand what is available, has been behind various efforts to provide compendia of methodologies and tools. These compendia have been compiled to support activities at the national level (Webb and Beh 2013; Climate UK 2012) and at the international level (UNFCCC Adaptation Knowledge Portal), but for the most part, they fall short of addressing the abovementioned questions (i.e. strengths, weaknesses, utility, adaptability and guidance).

The reasons behind the interest in using and translating existing tools are varied, but include questioning the need to develop a new tool (and expend limited resources) rather than take advantage of the credibility, robustness, breadth of experiences and support that are consolidated within existing tools. Of particular interest are those tools that have already been applied in different settings (e.g. sectors or countries) and by different users (e.g. decision-makers at different levels, NGOs or researchers) and for which guidance, case studies and support are available.

Adapting existing tools for use in different settings can, however, be challenging. Experience indicates that desirable characteristics in existing tools include availability, accessibility and openness for translation together with supporting guidance and documentation. Additionally, translation is more than just a question of language; it needs to reflect the decision-making culture and the experiences, capabilities and expectations of the intended user community.

The following sections of this paper draw together evidence and lessons learnt regarding the transfer and translation of tools using the example of the UK Climate Impacts Programme (UKCIP) Climate Adaptation Wizard ${ }^{3}$ (hereafter called 'the Wizard'). As pointed out by Palutikof et al. (in this special issue), there has been considerable research on decision-

\footnotetext{
${ }^{1}$ Decision-making frameworks commonly combine a conceptual framework that implements a particular approach to decision-making and a procedural framework that provides a step-by-step guide to implementation - this procedural component is often referred to as a decision tool (Randall et al. 2012). Consistent with the UNFCCC Adaptation Knowledge Portal, we will use the term 'tools' to refer to decision-making methods/ frameworks, including their associated decision-support tools.

2 Although most of these decision-support tools are available online, many (including the Wizard and the adapted tools referred to in this paper) are intended to be applied through a participatory approach. As such, they are not what we would identify as primarily a 'web-based' tool.

${ }^{3}$ http://www.ukcip.org.uk/wp-content/PDFs/UKCIP-Making-progress-FINAL.pdf—visited on 2018.04.02
} 
support tools, including that supporting adaptation decision-making. This paper specifically considers the body of research to propose a conceptual framework that supports the transfer and application of those decision-support tools in new contexts. Section 2 provides background and outlines the main components of the Wizard. Section 3 draws out from the literature principles that have credence and the potential to be applied in the 'real-world' translation of the Wizard based on two case studies (Section 4) and then, based on our reflections on lesson learnt, seeks within Section 5 to organise these into a conceptual framework supporting transferring and adapting decision-making tools.

\section{About the Wizard-setting the context}

The UKCIP was established by the UK Government in 1997 to coordinate research into the likely impacts of climate change in the UK. UKCIP's original remit was to provide decisionmakers with information on climate change impacts. However, over the years, its role evolved into the provision of information to support climate change adaptation. A key pillar of the support UKCIP has provided has been the Wizard, a decision-support approach (or framework) with linked tools and resources first launched in prototype form online in 2004 and which has been developed iteratively ever since.

The Wizard utilises a risk-based framing of adaptation as it offers a valuable approach to facilitating decision-making especially where information flows may be dynamic or imperfect and contain uncertainty. Recognising the value of this approach, UKCIP worked with the Environment Agency to develop a risk, uncertainty and decisionmaking framework to help UK organisations assess climate risks and make decisions on how to adapt (Willows and Connell 2003). Whilst this work was well received and considered conceptually robust, feedback from some practitioners suggested it was too theoretical and technically demanding to be readily applied by non-technical experts (West and Gawith 2005).

The first iteration of the Wizard reflected the key principles of a risk-based approach to decision-making but in a relatively non-technical, user-friendly format. It represents one of a number of adaptation planning approaches that have emerged since 2005 which recognise the importance of reassessment and the ability to change policies based on new insights conceptualised within a cyclical process (Haasnoot et al. 2013).

The Wizard was designed to help decision-makers move through a process from simple understanding of climate change to integration of climate change into decision-making by making use of the extensive resources available on the UKCIP website. More specifically, it aims to help organisations (both public and private) to raise awareness of climate change and adaptation; access information, tools and resources to help assess vulnerability to climate change; make the case for adaptation within organisations; develop a climate-resilient project, programme, policy or strategy; and develop and implement a climate change adaptation strategy. It should be noted that the Wizard was not designed as a standard template for the development of a climate adaptation strategy but rather as a process or risk-based approach with linked tools and resources to help generate information that can inform the development of such strategies, with the end goal of supporting and enhancing decision-making. It adopted a question-driven approach to take users through a five-step process to assess their climate risks and develop an adaptation response.

The five steps are: 
1) Getting started - designed to help set objectives, assemble a team and prepare for steps two to five;

2) Assess current vulnerability - critical to understanding existing risks and can help make the case for further work as it deals with the 'here and now';

3) Assess vulnerability to future climate change - takes into account future risks and explains how climate projections and data may be used in a practical way;

4) Identify, evaluate and select adaptation options - supports decisions on what action to take (or not);

5) Monitor and review - sets out the key factors to consider when reviewing effectiveness of adaptation efforts and ensuring future practice is informed by learning.

In its online form, the Wizard sets out a series of questions under each step. Each step provides background information and then sets out a task or exercise for users to complete to help them generate the information needed to answer the questions posed. Where appropriate, templates are provided to capture the necessary information. At the end of each step, a checklist prompts users to ensure that all actions have been undertaken. A list of useful resources that may help in completing the tasks is also provided as well as links to related UKCIP tools such as the Local Climate Impacts Profile (LCLIP) ${ }^{4}$ which is designed to support step 2. There have been four iterations of the Wizard, the latest in 2013. All versions were informed by user-testing and consultation with UK stakeholders including public and private sector organisations ranging from port authorities, logistics and communications organisations, supermarket chains, local governments, housing associations and trade bodies (UKCIP 2011).

\section{Principles for effective adaptation decision support}

To maximise the utility of decision-making methods and tools, it is essential to understand the key principles that support their transfer or translation to other contexts. Literature in the area of environmental decision-making and knowledge systems provides a starting point by identifying such principles:

P1: Understanding the perspective of the targeted end users.

P2: Credibility, relevance and legitimacy based on the stakeholders' needs and context.

P3: Co-development process involving producers and users.

P4: Guidance and sustained support throughout the development process and for application.

P5: Regular re-examination of user perceptions.

In their study of knowledge systems for sustainable development, Cash et al. (2003) underline the importance of understanding the perspective of the targeted end users $(P 1)$. Furthermore, they stress the need for information to be perceived by targeted stakeholders to be credible, relevant and legitimate $(P 2)$, including when managing the boundaries between knowledge and action. This notion is reinforced by Lemos et al. (2012) who state that the usability of knowledge is affected by three interconnected factors: the level and quality of interactions between those producing and those using (P3); the fit in terms of how users

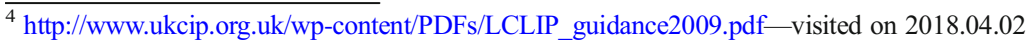


perceive that their needs are being met $(P 2)$; and the interplay between the knowledge reflected in the tool and that which they currently use (P2). Jones et al. (2014) examine the foundations of decision-making for adaptation and identify the importance of cultural and context appropriateness $(P 2)$ and consistency with policy and practice needs $(P 2)$ in providing effective decision support. They also emphasise well-considered processes over information products, recognising that the latter without the former are likely to be ineffective. We would go a step further based on our experience in developing, using and adapting the Wizard with users to stress the need for guidance and sustained support to build capacity in understanding and applying the process $(P 4)$ rather than simply applying the information it generates.

Based on this literature, it would appear reasonable to hypothesise that processes, if adapted to cultural context, are also likely to be more easily transferred than the information products they generate. Tools which facilitate regular re-examination of user perceptions (P5), and which connect those developing and using knowledge (P3), may also prove more agile in their application than those that do not.

Fundamental to effective decision support is targeted engagement of the intended user community throughout the development process (P3) such that there is social learning to support effective implementation (Pelling and High 2005; Cash et al. 2006; Reed et al. 2010). These aspects are an essential part of development-social support (P2)-if tools are to be used and owned by the intended users.

In addition, such tools are more than assistants to human dynamics for adaptation; they can be considered non-human actors that take part, framing the sociotechnical processes by influencing the human relationships (Callon 2004). That is why the process of codevelopment is centrally positioned $(P 3)$; it is the means by which the human actors can shape the required tool as a consequence of the intended behaviour and interactions, whilst rethinking and attributing meaning to past and current actions and behaviours as well as to the broad decision-making context.

\section{Supportive case studies-Portugal and Brazil}

This section reviews two case studies - Portugal and Brazil — where the Wizard was adapted, translated and applied outside the UK. Although both are Portuguese-speaking countries, the studies were undertaken independently with no cross-fertilisation of methodologies until after the end of each project. This review analyses both studies in light of the principles presented in the previous section.

\subsection{The Portuguese project-ClimAdaPT.Local}

The ClimAdaPT.Local project ${ }^{5}$ was funded by the European Economic Area (EEA) Grants scheme and ran between January 2015 and December 2016 under the coordination of the CCIAM Group at the Faculty of Sciences, University of Lisbon. The main goal of the project was to support the mainstreaming of climate change adaptation within municipal level planning, by providing training to local practitioners and the development of appropriate decision-support tools and methods. More specifically, one of the project's key objectives

\footnotetext{
$\overline{5 \text { http://climadapt-local.pt/—visited }}$ on 2018.04.02
} 
was to support the development of 26 municipal climate adaptation strategies (EMAAC in the Portuguese acronym) across the country.

To deliver on this goal, the project was designed to provide training to more than 50 municipal technicians across a number of sectoral planning areas through the use of a common methodological approach. The challenge of developing a common approach that could be simultaneously applied across multiple municipalities over the project's short time period resulting in the successful completion of their EMAAC was the principal driver for the development and deployment of a single, common decision-support tool. The choice had to be made between adapting a pre-existing tool versus developing a new tool.

\subsection{The Brazilian project—economy-wide adaptation to climate change}

The decision of the Brazilian Ministry of Environment (MMA) to support the development of a resource to assist civil society organisations (CSOs) in adapting to climate change was driven by a growing awareness of the need to increase the nation's resilience and by a number of key policy drivers. The latter included the Brazil National Adaptation Plan (NAP), the success of which depends on the ability to engage different sectors (private, public, academic and civil society) and on the decentralisation of its implementation.

The required decision-support tool is needed to foster and enable action-based involvement of CSOs in the national adaptation agenda and to support the subnational delivery of the NAP. The requirement was for a tool to guide decision-makers through a planning process anchored in the systemic approach of the CSO's programmes and projects. It would need to respect the contexts of the territories covered, include long-term horizons of analysis and allow for partnered development (with internal and external stakeholders).

Considering this requirement, it was recognised that it would be challenging to produce a new decision-support tool for the targeted CSOs, especially considering the diverse scopes of their programmes and projects. Thus, the decision was made to explore the applicability of existing tools that aimed to support organisations in building resilience to climate change impacts.

A partnership between MMA, the Centre for Sustainability Studies (GVces) of FGV EAESP and UKCIP, supported by the British Embassy, was established for the codevelopment of the required tool. The project took 1 year (2015) and was based on a participatory process. Eight Brazilian $\mathrm{CSOs}^{6}$ (each with two representatives) were engaged as a 'co-development working group' to adapt the Wizard through a process of three workshops, an online consultation, a round of interviews and a final meeting.

\subsection{Choosing which tool to adapt}

\subsubsection{Portugal}

During the initial phase of the Portuguese project, three different decision-support tools potentially relevant for the development of EMAACs were screened for applicability: (a)

\footnotetext{
${ }^{6}$ The CSOs that participated in the project were: Engajamundo, Fundação Grupo Boticário, Habitat for Humanity Brazil, ICLEI, IPAM - Institute of Environment Research of Amazon, SVPS - Society of Research in Wild Life and Environmental Education, WRI - World Resources Institute and WWF. They were involved through a relevant Brazilian civil society network called the Climate Observatory.
} 
UKCIP Adaptation Wizard; (b) Climate-ADAPT Adaptation Support Tool; and (c) PROVIA/ MEDIATION Adaptation Platform. ${ }^{7}$

The project had no preconceptions or formal requirement as to which tool to use, but the project team did recognise that time pressure (many parallel strategies being developed in a short timespan), perceived applicability to training, previous experience in using the tool and access to support from tool developers would need to be considered when selecting which one to use. The application of these criteria led to the choice of the Wizard.

\subsubsection{Brazil}

In the Brazilian case, 11 tools were identified and assessed as to their applicability using the following criteria: suitability for sectoral focus; clarity of methodologies; availability of case studies, guidelines and advice; databases on expected climate changes and impacts in the country; and support for monitoring and evaluation. Additional consideration was also given to the key messages of the Latin America Adaptation to Climate Change Forum (2013), ${ }^{8}$ namely:

- Facilitating information access and creating awareness is still one of the main barriers for structuring adaptation agendas;

- Material and contents are available but the main challenge remains in using them;

- Comprehension of climate change risks and opportunities is a powerful trigger for action.

With these considerations in mind, the UKCIP Adaptation Wizard was selected as the basis for the development of the CSOs support tool, with the following characteristics being considered advantageous:

- Simple and didactic, presenting clear steps based on a logical progression, well known and accepted internationally;

- Risk-based approach based on current and future climate vulnerabilities and making their relationships comprehensible to users;

- Linking to supportive material and providing means for users to engage with the process;

- Established knowledge, transparency and detail in the information available.

Together, these characteristics addressed the requirement for a feasible process (considering time, financial and human resources) that was capable of promoting a systemic approach within the CSOs' operating context.

\subsection{Adapting the tool}

\subsubsection{Portugal}

After choosing the Wizard, it then became necessary to contextualise, adapt and translate it to the particular Portuguese circumstances and needs of the project. To do

\footnotetext{
${ }^{7}$ http://www.mediation-project.eu/platform/ - visited on 2018.04 .02

${ }^{8}$ The Latin America Adaptation to Climate Change Forum was one of the milestones of the adaptation agenda in Brazil and inaugurated a series of research projects lead by GVces ( 2014) (http://gvces.com.br/estudos-sobreadaptacao-as-mudancas-do-clima-mma?locale=pt-br-visited on 2018.04.02)
} 
so, a core multidisciplinary project team with appropriate expertise and skills in climate change and adaptation concepts was assembled to support the required effort. Additionally, available Wizard supporting material would have to be turned into resources that could be used in formal training sessions and in engaging practitioners over the project's duration.

Because of previous interactions with UKCIP and the Wizard, the project team had a fairly good understanding of its five-step process and the resources available at each step. As a result, the overall direct engagement with the UKCIP team was relatively low. However, initial discussions seeking clarification of how the tool had been previously used, key meanings and the conceptual background behind its development proved extremely useful as prompts for sub-sequential translation and delivery efforts.

There was also the need to check carefully how to proceed with the translation of each step and respective resources and how best to adjust them to achieve the new purpose. This was done by applying a three-tier approach:

(1) The team reviewed available resources supporting each step and evaluated their relevance to the proposed work (e.g. since all municipalities are public, the focus needed to be on supporting public bodies rather than that targeting private companies);

(2) For each selected resource, the team considered whether it would be possible to properly contextualise it to the Portuguese situation (e.g. fit-to-purpose when applied to a different administrative unit); and

(3) For each resource that was considered relevant and applicable, the team assessed the possibility of adapting it for training purposes under a tight timeframe (i.e. could a specific task be presented in a training workshop, be used by practitioners over the course of a few weeks and yield relevant results?).

Because of the sequential nature of the work, there was also the need to ensure that each step could be accomplished in the available time and adjusted to be delivered in the four planned formal training sessions. Since the Wizard can be misinterpreted as being an input-output tool (i.e. input data and information automatically produces outputs and decisions), moderating expectations of both the core team (initially) and practitioners (during the project) was a task in itself.

Translating the Wizard and its supportive resources was a complex process due in part to cultural and linguistic issues, as well as availability of required complementary information (e.g. climate data at the required scale). Despite this, almost all the Wizard steps and associated tasks were, to some extent, considered relevant for the required support tool. However, because of the abovementioned considerations, it was decided to split step number 4 ('adaptation options') into two separate steps: one on identifying options and another on appraising selected options.

The resulting Portuguese version therefore consisted of six interconnected and sequential steps that retained the cyclic nature of the Wizard but that were renamed to reflect the Portuguese context (see Table 1). It was also decided to change the overall name of the tool as there is no contextually appropriate Portuguese translation for the word 'wizard'. The final adopted name was the ADAM methodology (a Portuguese acronym standing for 'Support to Municipal Adaptation Decisionmaking'). 
Table 1 List of steps in the UKCIP Adaptation Wizard and corresponding translated versions as used in the Portuguese and Brazilian cases

\begin{tabular}{|c|c|c|}
\hline UKCIP Adaptation Wizard & Portugal—ADAM tool & Brazil-CSO tool \\
\hline Step 1 - Getting started & Step 0 - Prepare the work & Step 1 - Project panorama \\
\hline $\begin{array}{l}\text { Step } 2 \text { - Current climate vul- } \\
\text { nerability }\end{array}$ & $\begin{array}{l}\text { Step } 1 \text { - Identify current vulner- } \\
\text { abilities }\end{array}$ & Step 2 - Understanding the climate \\
\hline $\begin{array}{l}\text { Step } 3 \text { - Future climate vulner- } \\
\text { ability }\end{array}$ & $\begin{array}{l}\text { Step } 2 \text { - Identify future vulnera- } \\
\text { bilities }\end{array}$ & \\
\hline \multirow[t]{2}{*}{ Step 4 - Adaptation options } & $\begin{array}{l}\text { Step } 3 \text { - Identify adaptation op- } \\
\text { tions }\end{array}$ & Step 3 - Adaptation options \\
\hline & $\begin{array}{l}\text { Step } 4 \text { - Appraise adaptation } \\
\text { options }\end{array}$ & $\begin{array}{l}\text { Step } 4 \text { - Prioritising risks and opportunities } \\
\text { Step } 5 \text { - Defining an adaptation plan }\end{array}$ \\
\hline Step 5 - Monitor and review & $\begin{array}{l}\text { Step } 5 \text { - Integrate, monitor and } \\
\text { review }\end{array}$ & $\begin{array}{l}\text { Step } 6 \text { - Implementing actions } \\
\text { Step } 7 \text { - Reflecting and learning } \\
\text { Step } 8 \text { - Thinking about the continuity } \\
\text { Step } 9 \text { - Stabilising partnerships and raising } \\
\text { resources }\end{array}$ \\
\hline
\end{tabular}

\subsubsection{Brazil}

The Wizard was analysed, translated into Portuguese and adjusted based on the context of the Brazilian national adaptation agenda and the CSOs' needs, capabilities, limitations and their programme/project-based approaches. ${ }^{9}$ The co-development working group discussed the aim, focus and application of the required tool, as well as the applicability of the Wizard to the Brazilian context.

It was a challenging process, but the agreement was that the existing logic and main elements of the Wizard remained applicable. Thus, the overall structure was retained, with some aspects of the Wizard being fully incorporated (with minor or no adjustments) and with some steps needing to be sub-divided whilst others were merged to create the final CSO adaptation planning tool (see Table 1).

Adjustments were introduced to reinforce the importance of co-development with the intended users; foster the systematic identification of relevant stakeholders and their potential roles; and support the development of a communication plan to engage with them.

Additionally, to foster collective reflection and learning based on adaptation as a continuous improvement and learning process, the step 'thinking about the continuity' was introduced with the aim of identifying which CSOs' stakeholders could potentially lead the implementation and monitoring of actions after the CSOs leave the territory or the specific initiative is completed.

Other changes made to the original Wizard reflected the needs of the organisations involved in the project, namely:

- Modifying the first step to allow for systematic consideration of the targeted group, the general and specific objectives (directly or indirectly related to adaptation to climate change) and the expected results of the programme/project under analysis;

\footnotetext{
${ }^{9}$ As the mission of the CSOs are delivered through their programmes and projects around which all the other activities are organised, the group involved in the project defined them as the focus for the tool and supportive resources to be developed.
} 
- Changing how concepts and guidelines are presented thereby allowing for exploring adaptation as a new 'lens' in an organisation's diverse set of programmes/projects rather than limiting its consideration to projects under an adaptation agenda;

- Splitting the monitor and review step into two to better fit the processes already followed by the CSOs in their programmes and projects.

- Integrating the analysis of current and future climate in a single step to reduce complexity and timing challenges in the application of the tool;

- Removing the task of identifying critical thresholds, since information was not readily available; and

- Adding the consideration of adaptive capacity to promote assessment of organisational and community readiness.

\subsection{Supporting the resulting tool}

\subsubsection{Portugal}

The adaptation and application of the required tool were supported through a series of formal training events focusing on each step. After each training event, the engaged municipal technicians were charged with conducting all the necessary assessments and complementary work and then presented their results at the subsequent event. Between these formal events (times between sessions ranged from 2 to 4 months depending on the needs of each step), the technicians and project team members met (meetings were divided into four regional areas) to evaluate results and to prepare for the subsequent step's training event. In addition, during these periods, all municipal technicians had access to support from the project team (via telephone, e-mail and face-to-face meetings) that acted as de facto knowledge brokers throughout the project. This additional support proved essential for keeping the work on track and providing opportunities for further clarification and answers to questions arising during their work.

To support the overall work and training, a final ADAM methodological guide and each of the proposed steps were published in the form of manuals that were distributed and presented at each training session. Each manual was composed of concepts and introductory training material, a description of work to be carried out in each step and respective tasks, time planning, checklists, glossary and additional resources as references and examples. Due to specific needs of municipal planning in Portugal, it was decided to allow for three additional resources: a guide and a tool on climate vulnerability of buildings (thermal comfort issues); a guide on economic appraisal of adaptation options; and a technical note on coastal vulnerability and adaptation.

The final ADAM training material (steps and resources) consisted of:

(1) Methodological guide (step 0 and presentation of overall approach);

(2) Evaluation of current vulnerabilities (step 1, including a version of the Local Climate Impacts Profile (LCLIP) renamed PIC-L in Portuguese);

(3) Evaluation of future vulnerabilities (step 2, including tailored climate change data factsheets, downscaled to the regional and local scale);

(4) Identification of adaptation options (step 3, including case studies and international examples); 
(5) Evaluation of adaptation options (step 4, including case studies, examples and tailored interactions with local agents and populations);

(6) Integration of adaptation in municipal territorial planning instruments (step 5)

(7) Evaluation of climate vulnerability of buildings (step 2, including a tailored GIS decision-support tool called BldAdaPT);

(8) Economic appraisal of adaption options (step 4, including examples of potential appraisal methods).

All this material was later pulled together into a single publication - the ADAM methodological guide - made available to all other Portuguese municipalities that did not participate in the ClimAdaPT.Local project, via the website and some local distribution channels. ${ }^{10}$

The project successfully managed to fulfil its objectives regarding tool development and application, training of the municipal technicians and supporting the development of the 26 EMAACs, for which the ADAM methodology was a valuable resource.

\subsubsection{Brazil}

The project's team supported the adaptation of the Wizard through three 2-day workshops. These presented and discussed the concepts and objectives of each step of the proposed tool and agreed on the dynamics required to implement it into targeted programmes or projects. They also included group exercises to test the logic and gather contributions.

To accomplish the objective of co-building a usable and effective tool, the facilitation role played by the UKCIP and GVces teams was crucial, along with the participatory methods applied to foster discussions and guide exercises. Besides facilitating the group meetings, it was important to provide basic information referring to each step-acting as knowledge brokers - and to support the participants when engaging their colleagues and internalising the learning and tool. Supportive mobilisation and engagement material was provided to the group.

Between events, participants were charged with undertaking the steps covered in the previous workshop, involving their teams and other areas of their organisations. Calls were held to support this internal exercise. The results, learning and difficulties were presented by the participants in the subsequent workshop to explore experiences, commonalities and differences. Based on this, the participants started to review their positions on the national and subnational adaptation agendas and to re-evaluate the challenges and barriers they previously assumed for their programmes and projects.

The process culminated in a final meeting that summarised all the findings, reflected on lessons learnt and shared plans for internalising and replicating the use of the tool in other programmes and projects. Finally, an open event was held by MMA to share knowledge and present the CSOs' cases and final products. These products included the adapted tool for CSOs and resulting strategies, tutorial videos and mobilisation and engagement materials, all available for download. ${ }^{11}$

\footnotetext{
${ }^{10}$ The final products are available for download in Portuguese at http://climadapt-local.pt/manuais/—visited on 2018.04.02

11 The final products are available for download in Portuguese and in English at http://adaptacao.gvces.com. br/\#nav-civil. - accessed on 2018.03.08
} 


\section{Discussion-cross-cutting lessons learnt and the resulting conceptual framework}

The two case studies illustrate the many decisions and actions required to adapt an existing decision-support tool for use in other situations. Drawing upon this evidence, and experience of working with others that have adapted the Wizard, we have identified lessons and challenges associated with adapting existing decision-support tools. In doing so, we have established a conceptual framework to support the transfer and adaptation of decision-making tools and their application within new contexts.

\subsection{Lessons learnt in assessing the potential for transferability}

The decision to translate rather than develop from first principles is often based on available time and resources (financial and human) and an appreciation that building on existing strengths comes with considerable advantages.

In selecting an appropriate tool and accessing whether it can be applied, the case studies from Brazil and Portugal highlight the importance of the following criteria:

- Demonstrated credibility of the approach and evidence that it has been applied in other areas and can be used in the targeted sector(s) - conferring legitimacy but also establishing trust and confidence;

- Clarity of the method - simple and logical process that can support learning within the targeted sector/organisation;

- Evidence of adaptability (open and transparent method)—supporting engagement in codevelopment;

- Consistency with decision-making approaches being used within the targeted sector/ organisation (e.g. risk-based) and with the political (national adaptation strategy and plans) and with methodological (participatory and training) approaches and requirements; and

- Applicability considering the available supporting data and information.

- The availability of supporting resources such as case studies (guidance and methodological material) and of technical support from the original developer.

The case studies indicate that these criteria are fundamental to a feasible translation process and product as they are also characteristics that are valued by the intended users.

\subsection{Lessons learnt on translating and adapting to a new context}

Having selected the tool, a range of factors have been identified that need to be considered in order to fully understand the extent and nature of adjustments and alterations required. These can be categorised as:

Conceptual — alignment with theoretical and practical understandings of adaptation

The concepts which underpin a decision-support tool may be an important factor in its selection, yet how these principles are articulated to potential users often need to be refined. For example, understanding that the Wizard is a means to support exploring and learning about adaptation towards developing a strategy and plan rather than an input-output resource is 
central to its effective application. This conceptualisation of the nature of the decision-support tool required clarification from the start, as well as reinforcement throughout its development and implementation.

In other cases, adjustments to the tool are needed to ensure it is better aligned with how adaptation is perceived, understood or implemented. This may require making elements more consistent with the context in which it will be applied (e.g. adjusting to reflect an organisational, programmatic or project-centred approaches), the sector or type of organisation that may use it and the capabilities and limitations of users. In Brazil, the first step of the Wizard was modified to better reflect the needs of the target group and of the objectives and expected results of the relevant project/programme. In Portugal, the adaptation option step was split into two steps - one to identify adaptation options and a second to appraise those options, and additional support material was added to reflect the specific nature of municipal planning in Portugal.

Cultural—reflecting the decision-making culture and accepted procedures

The need to appropriately reflect the culture often requires changes to the structure and format and to the way concepts and guidance are presented and emphasised. This is particularly important when considering the engagement of internal and external stakeholders (i.e. crucial in developing and delivering a consistent, effective and sustainable adaptation agenda, including in implementing, monitoring and evaluating) where hierarchy and social protocols vary.

Linguistic - more than just a simple translation

Although both studies were translated into Portuguese, the translation had to be appropriate to the use of language within the specific country and organisations. This was also the case when the Wizard was adapted for use in California ${ }^{12}$ where the English had to be translated to reflect linguistic subtleties. An example of this was the fact that the word 'wizard' does not have a contextual equivalent in Portuguese.

Political—alignment with political landscape, processes and capacities

Adjustments are needed to reflect the political drivers related to the respective adaptation and other sectoral policies, agendas and pressures, as well as their relative maturity. This should include consideration of the relative maturity of impact, vulnerability, risk and adaptation assessment processes, the presence of an enabling environment, and pressures and willingness to accept adaptation as a legitimate activity. Specific examples include adjustments to the assessment steps and focusing on monitoring and evaluation to ensure they are consistent with the developing nature of related policies, agendas and capabilities.

Resources - alignment with capabilities and the availability of supportive data

${ }^{12}$ Integrated Risk Management Roadmap http://www.carpediemwest.org/resources/roadmap/—visited on 2018.04.02. 
The requirements of the decision-support tool must be consistent with the availability of resources, including information and data availability. The lack of both these can be a barrier to action but also a rationale for inaction. As such, specific attention during the co-development and training phases is critical to creating and establishing a fit-for-purpose support tool. Examples of adjustments relate to reducing the complexity of the assessment process (e.g. reducing the number of time periods to be considered, eliminating the need to identify thresholds and simplifying the costing support tool), increasing the guidance and background information available and providing access to information (e.g. regional climate trends and potential impacts).

\subsection{Lessons learnt on co-development and social learning}

Engagement of the user community's representatives throughout the entire translation process is often critical to the uptake and sustainability of a given tool, however robust it may be conceptually. These engagement processes also highlight the relevance of social learning and iterative approaches to tool development in effective implementation. In this regard, four further lessons can be inferred:

\section{Engagement and commitment to the process}

Three critical issues were identified in relation to engagement: (i) the importance of identifying and understanding the individuals and organisations that make up the target user community or sector, including their motivations and needs; (ii) establishing a common understanding of the concepts around the decision-making tool, for instance vulnerability, resilience, risk and impact; and (iii) building confidence in the relevance and benefits of the tool. A well-tested and proven tool can reduce anxiety and resistance but this may only be sustained if concerns are addressed and reflected in iterative adjustments to the approach.

\section{Establishing a community of practice}

By assuming the role of a community of practice $(\mathrm{CoP})$, those engaged in co-development of a tool see each other as peers and share experiences and knowledge by communicating frequently including through informal channels (Pelling and High 2005). Good facilitation (Cundill et al. 2014) provides an engaging space for participants, providing equal opportunities for all and supporting a process that builds upon the practitioners' experiences. Where this CoP engages and can provide feedback to the original tool developers, there is the additional advantage of drawing on the broader experiences beyond the development and use of the original tool. This focus and the connection with practice are essential for successful transferability. The relationships established through a $\mathrm{CoP}$ are also vital to sustainability beyond an initial co-development project.

\section{Coordination of engagement}

Essential and practical considerations in establishing co-ownership of the tool are (i) the coordination and scheduling of engagement and (ii) designing each event such that the intended user community is appropriately represented and prepared to engage in co- 
development and testing. This coordination is critical in sustaining engagement and identifying corrective measures.

Learning through conflict and reflexivity

The discussions involved in the co-development of the translated tool establish a rich learning process for all those involved. They provide opportunities to bring forward and reflect on conflicts arising from differing perspectives, needs and interests with respect to the decision-support tool and to introduce innovative ideas. As such, the co-development process should provide opportunities to reflect on potential conflicts (both individually and collectively) and also to promote reflexivity throughout the entire process (Chandler 2014).

Figure 1 brings together the components and lessons outlined above in a conceptual framework. As such, this framework articulates the key components required when selecting, translating, applying and sustaining a tool in a new context.

\section{Conclusions}

In presenting the lessons learnt and challenges identified from translating and adapting the Wizard, we provide insights that have broader implications for those considering transferring other adaptation decision-support tools to their specific circumstances. These insights, captured in the proposed conceptual framework, should also be seen as guidance to developers wanting to see their decision-support tools used more widely. Further developments in this area are expected over the next few years - e.g. innovative data visualisation techniques, interactive training support tools and new ways of dealing with conflicting knowledge and evidence-

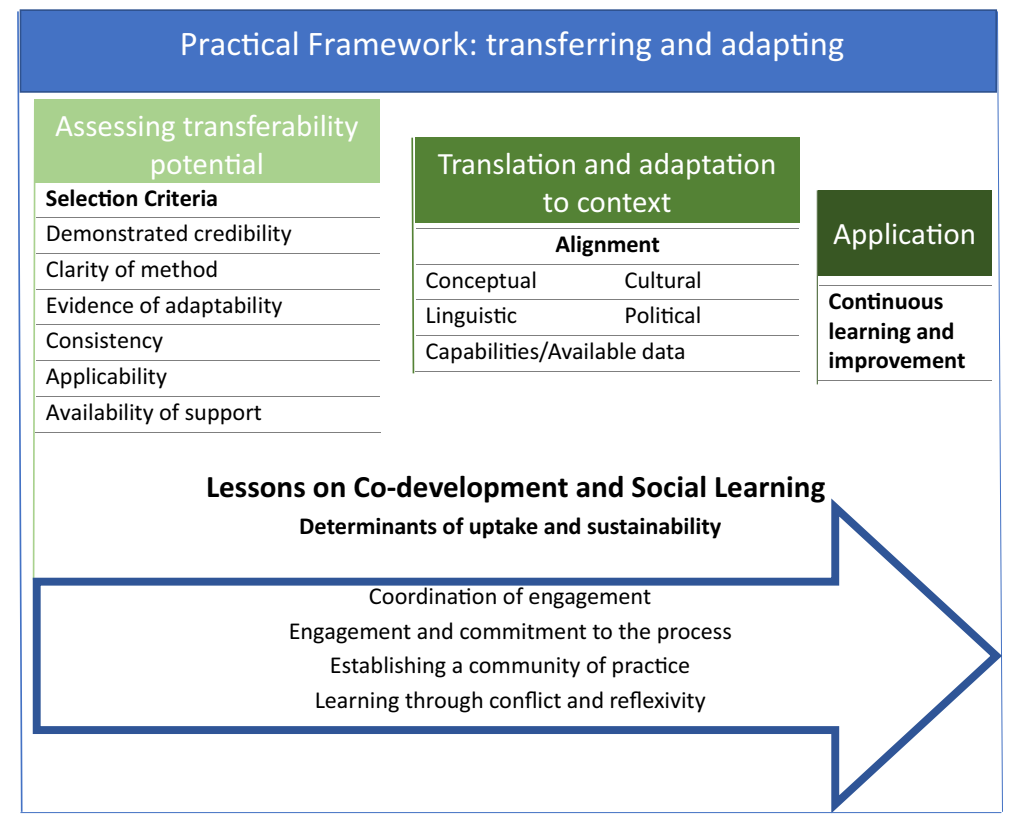

Fig. 1 A conceptual framework supporting selecting, translating, applying and sustaining decision-making tools 
initiating new relationships between human and non-human actors in the sociotechnical systems and creating additional challenges that may also benefit from the lessons presented here.

Open Access This article is distributed under the terms of the Creative Commons Attribution 4.0 International License (http://creativecommons.org/licenses/by/4.0/), which permits unrestricted use, distribution, and reproduction in any medium, provided you give appropriate credit to the original author(s) and the source, provide a link to the Creative Commons license, and indicate if changes were made.

\section{References}

BalticClimate Toolkit (2012) https://www.toolkit.balticclimate.org/—visited 2017.08.25

Bours D, McGinn C, Pringle P (2013) Monitoring \& evaluation for climate change adaptation: a synthesis of tools, frameworks and approaches. SEA Change CoP, Phnom Penh and UKCIP, Oxford

Callon M (2004) The role of hybrid communities and socio-technical arrangements in the participatory design. Journal of the Center for Information Studies 5(3):3-10

Capela Lourenço T, Swart R, Goosen H, Street RB (2016) The rise of demand-driven climate services. Nat Clim Chang 6(1):13-14. https://doi.org/10.1038/nclimate2836

Cash DW, Clark WC, Alcock F, Dickson NM, Eckley N, Guston DH, Jager K, Mitchell RB (2003) Knowledge systems for sustainable development. PNAS 100(14):8086-8091

Cash DW, Adger W, Berkes F, Garden P, Lebel L, Olsson P et al (2006) Scale and cross-scale dynamics: governance and information in a multilevel world. Ecol Soc 11(2)

Chandler D (2014) Beyond neoliberalism: resilience, the new art of governing complexity. Resilience 2(1):4763. https://doi.org/10.1080/21693293.2013.878544

Climate UK (2012) Review of adaptation tools, sustainability west midlands working. http://www. sustainabilitywestmidlands.org.uk/our-projects/climate-uk-review-of-adaptation-tools/. Accessed 31 Mar 2018

Cundill G et al (2014) Social learning for adaptation: a descriptive handbook for practitioners and action researchers. IDRC/Rhodes University/Ruliv

GVces (2014).Studies on adaptation to climate change - Brazil Ministry of Environment. Available at: http:/gvces. com.br/estudos-sobre-adaptacao-as-mudancas-do-clima-mma?locale=pt-br-visited on 2017.07.04

Haasnoot M, Kwakkel JH, Walker WE, ter Maat J (2013) Dynamic adaptive policy pathways: a method for crafting robust decisions for a deeply uncertain world. Glob Environ Chang 23(2):485-498

Jones RN, Patwardhan A, Cohen SJ, Dessai S, Lammel A, Lempert RJ, Mirza MMQ, von Storch H (2014) Foundations for decision making. In: Field CB, Barros VR, Dokken DJ, Mach KJ, Mastrandrea MD, Bilir TE, Chatterjee M, Ebi KL, Estrada YO, Genova RC, Girma B, Kissel ES, Levy AN, MacCracken S, Mastrandrea PR, White LL (eds) Climate Change 2014: Impacts, Adaptation, and Vulnerability. Part A: Global and Sectoral Aspects. Contribution of Working Group II to the Fifth Assessment Report of theIntergovernmental Panel on Climate Change. Cambridge University Press, Cambridge, United Kingdom and New York, NY, USA, pp. 195-228

Lemos MC, Kirchhoff C, Ramparasad V (2012) Narrowing the climate information usability gap. Nat Clim Chang 2:789-794. https://doi.org/10.1038/nclimate1614

Pelling M, High C (2005) Social learning and adaptation to climate change. Benfield Hazard Research Centre. Disaster Studies Working Paper 11. June 2005

PROVIA (2013) PROVIA Guidance on assessing vulnerability, impacts and adaptation to climate change. Consultation document, United Nations Environment Programme, Nairobi, Kenya, 198 pp . http://www. adaptation-undp.org/sites/default/files/downloads/provia-guidance-nov2013.pdf-visited 2018.03.31

Randall A, Capon T, Sanderson T, Merrett D, Hertzler G (2012) Choosing a decision-making framework to manage uncertainty in climate adaptation decision-making: a practitioners handbook. National Climate Change Adaptation Research Facility, Gold Coast 25 pp

Reed M, Evely AC, Cundill G, Fazely IRA, Glass J, Laing A, Stringer L (2010) What is social learning? Ecol Soc

UKCIP (2011) Making progress: UKCIP \& adaptation in the UK. UK Climate Impacts Programme, Oxford, UK. http:/www.ukcip.org.uk/wp-content/PDFs/UKCIP-Making-progress-FINAL.pdf — visited 2017.08.25

West CC, Gawith MJ (eds) (2005) Measuring progress: preparing for climate change through the UK climate impacts Programme. UKCIP Technical Report. UKCIP, Oxford, 71pp

Willows RI, Connell RK (2003) Climate adaptation: risk, uncertainty and decision-making. UKCIP technical report. UKCIP, Oxford $71 \mathrm{pp}$ 